\title{
臭化カリウム還元/水素化物発生原子吸光法による 水試料中のセレンの定量
}

\author{
玉利 祐三 ${ }^{\circledR *}$, 小椋 広道* \\ Determination of selenium in water samples by hydride-generation AAS \\ with the potassium bromide reduction of selenium \\ Yuzo TAMari and Hiromichi Ogura* \\ * Konan University, 8-9-1, Okamoto, Higashinada-ku, Kobe-shi, Hyogo 658 \\ (Received 24 October 1996, Accepted 20 January 1997)

\begin{abstract}
The concentration of selenium was determined by AAS equipped with a hydrogen sele-
\end{abstract} \\ nide generation system in which selenium(VI) was not detected, but selenium(IV) was \\ measured. For a total selenium determination, selenium(VI) should be reduced to sele- \\ nium(IV) by boiling it for $60 \mathrm{~min}$ with a $1.5 \%$ potassium bromide solution adjusted to a \\ $0.5 \mathrm{~mol} / \mathrm{l}$ hydrochloric acid solution. In this method, almost $100 \%$ of the selenium(VI) \\ and selenium(IV) were recovered from $50 \mathrm{ml}$ of distilled-water and mineral-water sam- \\ ples. This method was applied to standard reference river-water sample supplied from \\ Japan Society for Analytical Chemistry; our data, $5.0 \pm 0.1 \mathrm{ng} / \mathrm{ml}$, agreed well with the \\ certified selenium concentration, $5.2 \pm 0.3 \mathrm{ng} / \mathrm{ml}$.
}

Keywords : determination of total selenium; AAS; hydrogen selenide; potassium bromide reduction; water sample.

\section{1 緒—言}

近年, 環境中の種々の化学物質の人体に対する影響か ら，1993 年 3 月水質污濁に関する環境基準が大幅に強 化・改正され，新たにセレンが測定項目に追加されるよ うになった. 又, 1993 年 12 月には, 水道水の安全性の 確保を目的として水道法に基づく飲料水についても新水 質基準が施行され，セレンについては $10 \mathrm{ppb}$ 以下とい う登しい基準值 ${ }^{122)}$ が設けられた。すすわち，この基準 值では, 試水中の全セレンが対象となっている. 又, セ レンの検查方法についても比較的簡便な水素化物発生原 子吸光分析 ${ }^{2)}$ (HG-AAS) が記載されている. しかし, HG-AAS では, 測定溶液中のセレン (VI). は検出され

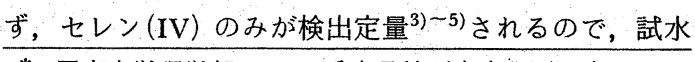

中の全セレンを定量するためにはセレン(VI) をセレ ン（IV) に還元した後, 測定する必要がある.

セレン(VI) のセレン(IV) への還元には, 一般に 6 $\mathrm{mol} / \mathrm{l}$ 以上の塩酸溶液で煮沸処理 ${ }^{6}$ されているが, この 還元法では試料酸分解後の数 $\mathrm{ml}$ といった小容量試料に ついては有効であるが, 水試料を対象とした大容量試料 の処理には不向きである. 臭化カリウムを用いる還元法 は, 比較的低塩酸濃度でセレンを還元できる利点から, 天然水 $200 \sim 400 \mathrm{ml}$ 中のセレン (VI) をセレン(IV) に するために, 中ロらブ $1.3 \mathrm{~mol} / \mathrm{l}$ 塩酸酸性とした $4 \%$ 臭化カリウム溶液を $90 \sim 100^{\circ} \mathrm{C}$ で 25 分間加熱した後, 試水中のセレン(IV) を2,3-ジアミノナフタレンを用い て蛍光定量した. 又, 田中 ら ${ }^{3)}$ は, 天然水 $400 \mathrm{ml}$ を試 料溶液として溶存するセレン $(\mathrm{VI})$ を $1 \mathrm{~mol} / \mathrm{l}$ 塩酸酸性 とした $1.6 \%$ 臭化カリウム溶液を $80^{\circ} \mathrm{C}$ で 120 分間加熱 
してセレン(IV) とした後, テトラヒドロホウ酸ナトリ ウムによりセレン化水素とし液体窒素コールドトラップ に冷却捕集し，これを再気化して原子吸光法により定量 した。しかし, 飲料水, 地下水, 河川水, 排水等の実試 料中の ppt から ppb レベルの極微量セレンを定量する には，添加する試薬からのセレンの污染を避けるため に, 試料溶液に添加する試薬数之試薬量をできる限り少 なくする必要がある。これまでの臭化カリウムを還元剛 とするセレンの分析法では，これらの点が十分に検討さ れていなかったため, 本研究ではセレン(VI) 還元時の 塩酸濃度, 臭化カリウム添加量, 還元処理法等の極微量 セレンを定量するための詳細な検討を行い，処理した試 料溶液を $3.6 \mathrm{~mol} / 1$ 塩酸酸性として直接 HG-AAS によ り試水中の全セレンの定量する方法について検討を行っ た.

\section{2 実 験}

\section{$2 \cdot 1$ 試 薬}

セレン (IV) 標準溶液: 金属セレン(和光純薬製，純 度 $99.999 \%) \quad 0.1 \mathrm{~g}$ を硝酸 (61\%) $2 \mathrm{ml}$ 及び過塩素酸 $(60 \%) 2 \mathrm{ml}$ に溶解し，ホットプレート上で加熱溶解 し, 過塩素酸白煙が生じてから数分間乾固しないように 加熱濃縮した後, セレン(VI) をセレン(IV) に還元す るために $11 \mathrm{~mol} / 1$ 塩酸 $5 \mathrm{ml}$ を加えて 3 分間煮沸した. 冷却後, 水を加えて $100 \mathrm{ml}$ とした $(1000 \mathrm{ppm}$ 保存溶 液).七レン (VI) 標準溶液：セレン酸ナトリウム(和光 純薬製，純度 $97 \%) 0.2393 \mathrm{~g}$ を水に溶解後, 硝酸 0.5 $\mathrm{ml}$ を加え，水を加えて $100 \mathrm{ml}$ とした（1000 ppm 保存 溶液).

テトラヒドロホウ酸ナトリウム $(0.75 \mathrm{w} / \mathrm{v} \%)$ 溶液: テトラヒドロホウ酸ナトリウム (和光純薬製) $3.75 \mathrm{~g}$ 及 び水酸化ナトリウム $0.5 \mathrm{~g}$ を水に溶解し $500 \mathrm{ml}$ とした。 なお,この溶液は実験の直前に調製した。

塩酸, 硝酸, 過塩素酸は,すべて精密分析用試薬（和 光純薬製) をそのまま用いた. 臭化カリウムは特級試薬 (和光純薬製) を, その他の試薬も特級試薬を用いた.

\section{$2 \cdot 2$ 装 置}

原子吸光分光光度計（同社製 Z-6100 型）及び加熱石 英セル付属水素化物発生装置 (日立製作所製 HFS-2 型) を用いた。なお，セレン分析のための最適測定条件は既 報 ${ }^{4) 5)}$ のとおりである。但し, 測定溶液及びキャリヤー 塩酸溶液は共に $3.6 \mathrm{~mol} / 1$ 塩酸溶液を用いた。この測定 条件の下では試料溶液中のセレン(VI) は検出されず,

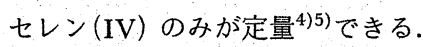

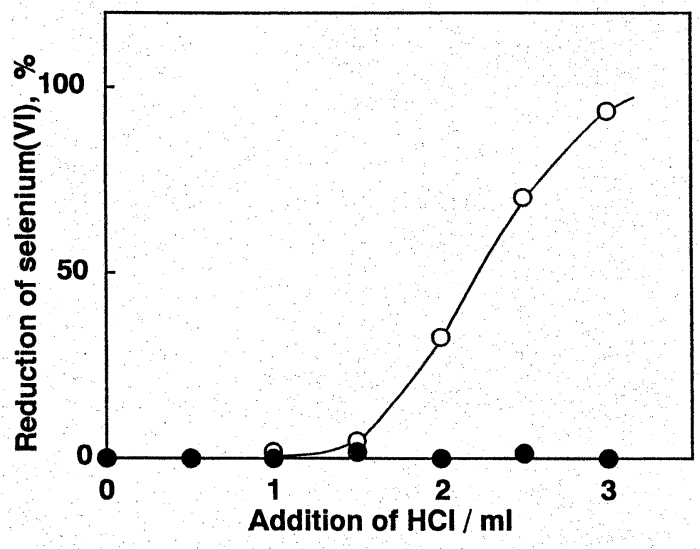

Fig. 1 Effect of the addition of hydrochloric acid to a standard selenium(VI) solution at room temperature

$O: 11 \mathrm{~mol} / 1 \mathrm{HGl} ; 6 \mathrm{~mol} / 1 \mathrm{HGl}$ addition to 1 $\mathrm{ml}$ of solution containing $500 \mathrm{ng}$ of selenium (VI).

\section{$2 \cdot 3$ 還元処理}

試水 $50 \mathrm{ml}$ を゙ーカー $(100 \mathrm{ml})$ に採り, $6 \mathrm{~mol} / \mathrm{l}$ 塩 酸 $4.5 \mathrm{ml}$ 及び臭化カリウム $0.75 \mathrm{~g}$ を加え溶解する. ビーカーに時計皿をかぶせ, $200^{\circ} \mathrm{C}$ に調節したホットプ レート上で 60 分間煮沸する. 水冷後, 一定容の塩酸を 加え, 水で全容を $100 \mathrm{ml}$ とし $3.6 \mathrm{~mol} / 1$ 塩酸溶液を調 製しここれを測定溶液とした。

\section{3 結果と考察}

\section{$3 \cdot 1$ 溶液調製に用いる濃塩酸によるセレンの還元}

セレン $(\mathrm{VI})$ 標準溶液の調製時に $11 \mathrm{~mol} / \mathrm{l}$ 塩酸を添加 するようなことがあれば，Fig. 1 より明らかなように， 添加による発熱反応のために，かなりの割合のセレ ン(VI) がセレン(IV) に還元されることが分かった. 従って, 試料溶液及びセレン(VI) 標準溶液の調製, あ るいはセレンの酸化状態分別分析の目的には, $11 \mathrm{~mol} / \mathrm{l}$ 塩酸の添加は避けなければならない. $11 \mathrm{~mol} / 1$ 塩酸の添 加と同一の条件で, $6 \mathrm{~mol} / 1$ 塩酸を添加したが, この場 合にはセレン(VI) のセレン(IV)への還元は全く見ら れなかった。

\section{$3 \cdot 2$ 還元剤の検討}

Table 1 に示す 6 種類の還元剤についてセレン (VI) のセレン(IV) への還元効果を検討した. 但し，セレ ン (VI) $500 \mathrm{ppb}$ 標準溶液 $1 \mathrm{ml}$ を含む $0.1,0.5,1.0,2.0$, $3.6 \mathrm{~mol} / 1$ の塩酸溶液を調製し, 各還元剤の濃度が 
Table 1 Reduction of selenium(VI) with different reducing reagents at room temperature

\begin{tabular}{lcc}
\hline \multicolumn{1}{c}{ Reducing reagent $^{\text {a) }}$} & $\begin{array}{c}\text { Conc. of } \\
\mathrm{HCl}^{-1}\end{array}$ & $\begin{array}{c}\text { Reduction of } \\
\mathrm{me}(\mathrm{VI}), \%\end{array}$ \\
\hline Potassium bromide & $0.1 \sim 3.6$ & $9 \sim 22$ \\
Hydroxylamine hydrochloride & $0.1 \sim 3.6$ & $0 \sim 2$ \\
Sodium oxalate & $0.1 \sim 3.6$ & $0 \sim 2$ \\
Sodium tartrate & $0.1 \sim 3.6$ & $0 \sim 2$ \\
Potassium iodide $^{\mathrm{b})}$ & $0.1 \sim 3.6$ & $29 \sim 33$ \\
L-Ascorbic acid $^{\text {b) }}$ & $0.1 \sim 3.6$ & $0 \sim 3$ \\
\hline
\end{tabular}

a) Concentrations of all the reducing reagents were prepared to be $12.5 \%$ solutions, and $500 \mathrm{ng}$ of selenium(VI) were added. b) Red elemental selenium deposit was found, when a few $\mathrm{mg}$ amounts of selenium(VI) were used with potassium iodide and Lascorbic acid.

$12.5 \%$ となるようにした。 室温で数分間放置後, 試料 溶液中のセレン (IV) を定量し，七レン(VI) のセレ ン (IV) への還元率を求めた。その結果, 塩酸ヒドロキ シルアミン, シュウ酸ナトリウム, 酒石酸ナトリウム及 び $\mathrm{L}$-アスコルビン酸では, いずれの酸性度においても 還元効果はほとんど見られなかった. ヨウ化カリウムを 用いた場合には，調製した溶液の酸性度にかかわらずほ ぼ一定 29 33\% のセレン (IV) への還元率が得られた が,これは後にセレン(VI) 数 $\mathrm{mg}$ を含む溶液で同様な 実験を行った結果，添加したセレン(VI) が赤色状の金 属セレンまで還元されていることが分かった． 従って, ヨウ化カリウムはセレン(VI) のセレン (IV) への還元 には不適当であることが分かった. 又, L-アスコルビン 酸についても同様に赤色状の金属セレンまで還元されて いることが分かった．しかし，臭化カリウムを用いた場 合には, $0.1 \sim 3.6 \mathrm{~mol} / 1$ 塩酸溶液中でセレン $(\mathrm{VI})$ の 9 22\% がセレン(IV) に還元されたので，本研究では 臭化カリウムによるセレンの還元について詳細に検討を 行うことにした.

\section{$3 \cdot 3$ 臭化カリウムによる還元}

\section{$3 \cdot 3 \cdot 1$ 塩酸濃度及び臭化カリウム濃度の影響 七} レン (VI) $500 \mathrm{ppb}$ 標準溶液 $1 \mathrm{ml}$ を含み, 溶液の塩酸濃 度をそれぞれ $0.1,0.25,0.5,1.0,1.5 \mathrm{~mol} / 1$ とした $15 \mathrm{ml}$ 溶液に, 臭化カリウム $0.075 \sim 0.375 \mathrm{~g}$ を加えて $2 \cdot 3$ 項 の操作に従い，ホットプレート上で 45 分間煮沸処理を 行い，塩酸濃度及び臭化カリウム濃度に対するセレ ン（VI）のセレン (IV)への還元率を求めた．結果を

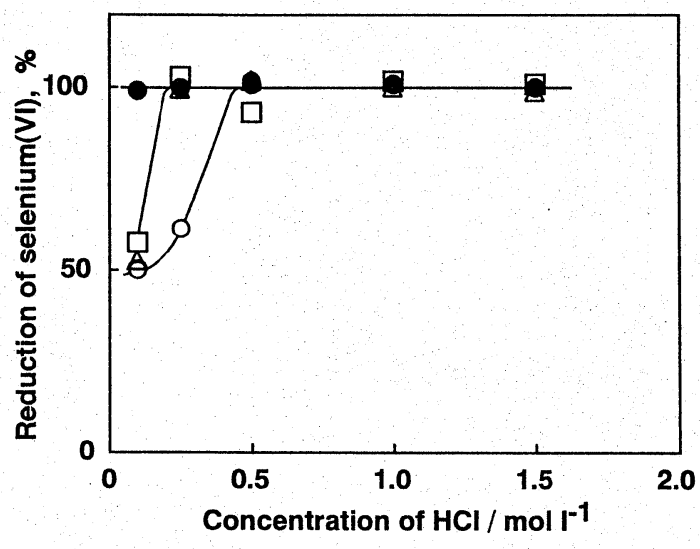

Fig. 2 Effect of the concentration of hydrochloric acid and potassium bromide on the reduction of selenium(VI)

$\bigcirc: 0.5 \% ; \triangle: 1.0 \% ; \square: 1.5 \% ; \bigcirc: 2.5 \%$ of $\mathrm{KBr}$ solutions ( $15 \mathrm{ml})$ containing $500 \mathrm{ng}$ of selenium(VI), boiling it covered with a watchglass for $45 \mathrm{~min}$.

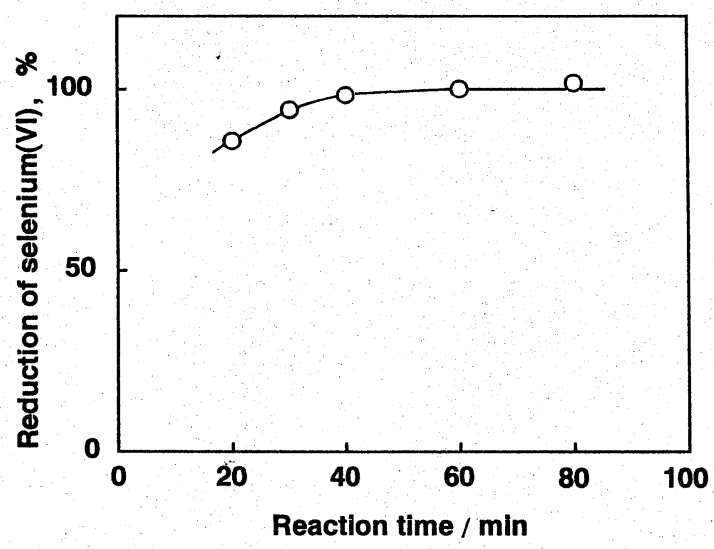

Fig. 3 Effect of the reaction time on the reduction of selenium(VI)

Reducing condftion: $0.5 \mathrm{~mol} / 1 \mathrm{HCl}$ and $1.5 \% \mathrm{KBr}$ solutions, and then boiling a $50 \mathrm{ml}$ of solution containing $2000 \mathrm{ng}$ of selenium (VI).

Fig. 2 に示す. 塩酸濃度が高くなるにつれて, 又臭化力 リウム濃度が高くなるにつれてセレンの還元率はほぼ $100 \%$ となった．陸水，排水など実試料中の全セレンを 定量する目的ならば，添加する塩酸量をできる限り少な くし，試薬中の不純物セレンによる污染の影響をできる だけ少なくするためには添加する還元剤濃度を低くする 
Table 2 Recoveries of selenium(IV) and selenium(VI) from the $50 \mathrm{ml}$ of a water sample by the recommended method

\begin{tabular}{|c|c|c|c|}
\hline \multicolumn{2}{|c|}{ Se added/ng } & \multirow{2}{*}{ Se found/ng } & \multirow{2}{*}{$\begin{array}{l}\text { Recovery of } \\
\text { selenium, \% }\end{array}$} \\
\hline $\mathrm{Se}(\mathrm{IV})$ & $\mathrm{Se}(\mathrm{VI})$ & & \\
\hline \multicolumn{4}{|c|}{ In distilled water } \\
\hline 2000 & & 2000 & 100 \\
\hline 2000 & & 1990 & 99.5 \\
\hline 2000 & & 2040 & 102 \\
\hline \multirow[t]{7}{*}{2000} & & 2000 & 100 \\
\hline & & & $\overline{\text { Av. } 100 \pm 1.1}$ \\
\hline & 2000 & 2000 & 100 \\
\hline & 2000 & 2020 & 101 \\
\hline & 2000 & 2010 & 100 \\
\hline & 2000 & 2040 & 102 \\
\hline & & & $\overline{\text { Av. } 101 \pm 1.0}$ \\
\hline 1000 & 1000 & 2010 & 100 \\
\hline 1000 & 1000 & 2040 & 102 \\
\hline 1000 & 1000 & 2050 & 102 \\
\hline \multirow[t]{2}{*}{1000} & 1000 & 2050 & 102 \\
\hline & & & Av. $102 \pm 1.0$ \\
\hline \multicolumn{4}{|c|}{ In mineral water } \\
\hline 0 & 0 & 0 & \\
\hline 0 & 0 & 0 & \\
\hline \multirow[t]{2}{*}{0} & 0 & 0 & \\
\hline & & $\overline{\text { Av. } 0}$ & \\
\hline 2000 & & 1980 & 99.0 \\
\hline 2000 & & 2000 & 100 \\
\hline \multirow[t]{6}{*}{2000} & & 2010 & 101 \\
\hline & & & $\overline{\mathrm{Av} .100 \pm 1.0}$ \\
\hline & 2000 & 2030 & 102 \\
\hline & 2000 & 1950 & 97.5 \\
\hline & 2000 & 1980 & $\begin{array}{r}99.0 \\
\end{array}$ \\
\hline & & & $\overline{\text { Av. } 100 \pm 1.7}$ \\
\hline
\end{tabular}

Reducing condition: $0.5 \mathrm{~mol} / 1 \mathrm{HCl}$ and $1.5 \% \mathrm{KBr}$ solutions, and then boiling for $60 \mathrm{~min}$ in a beaker covered with a watchglass; Mineral water: containing $16.7 \mathrm{ppm}$ of $\mathrm{Na}, 0.3 \mathrm{ppm}$ of $\mathrm{K}, 5.4 \mathrm{ppm}$ of $\mathrm{Mg}$ and $27.2 \mathrm{ppm}$ of $\mathrm{Ca}$

ことが望まれるので, 本研究では $0.5 \mathrm{~mol} / 1$ 塩酸酸性溶 液かつ $1.5 \%$ 臭化カリウム濃度でセレンの還元処理を行 うことにした。

\section{$3 \cdot 3 \cdot 2$ 還元時の反応時間の影響 七レン (VI) 2} $\mathrm{ppm}$ 標準溶液 $1 \mathrm{ml}, 6 \mathrm{~mol} / 1$ 塩酸 $4.5 \mathrm{ml}$ を加え水で 50 $\mathrm{ml}$ とし, $0.5 \mathrm{~mol} / 1$ 塩酸溶液を調製する. 臭化カリウム $0.75 \mathrm{~g}$ を加え, $2 \cdot 3$ 項の操作に従いセレンの還元に及ぼ す煮沸反応時間の影響について検討を行った. Fig. 3 に 示すように, 40 分以上の加熱処理でセレン(VI) のほぼ $100 \%$ が還元できたので, 本研究では 60 分間の煮沸処
Table 3 Analytical values of total selenium in Japan Society for Analytical Chemistry Standard Reference Materials of Japanese River Water (ng/ml)

\begin{tabular}{lcc}
\hline $\begin{array}{c}\text { This method } \\
\text { (KBr reduction) }\end{array}$ & $\begin{array}{c}\text { Fluorometry } \\
\text { (HCl reduction) }\end{array}$ & $\begin{array}{c}\text { Certified value/ } \\
\mathrm{ng} \mathrm{ml}^{-1}\end{array}$ \\
\hline 5.15 & 5.08 & \\
4.89 & 5.40 & \\
$\frac{5.06}{\text { Av. } 5.0 \pm 0.1}$ & $\frac{5.16}{\text { Av. } 5.2 \pm 0.2}$ & $5.2 \pm 0.3$ \\
\hline Fluorometry: 2,3-diaminonaphthalene (DAN) ex- \\
traction method
\end{tabular}

理を行うことにした

$3 \cdot 3 \cdot 3$ セレン(IV) 及び (VI) の回収率 $3 \cdot 3 \cdot 1$ 及び $3 \cdot 3 \cdot 2$ の結果で得られた最適条件下, すなわち $2 \cdot 3$ 項の操作に従いセレンの添加回収実験を行った．結果を Table 2 に示す. 蒸留水にセレンを添加し本法の還元処 理を行ったところ，セレン四価，六価及び四価・六価混 合体では，それぞれほぼ $100 \%$ の還元率が得られた.

又, 市販のミネラルウオーターを試料として同様の還元 処理を行ったところ，ほぼ $100 \%$ の還元率を得ること ができ，実試料への適用が可能であることが分かった.

3•3・4 標準河川水への適用 本法を日本分析化学 会より供給されている標準河川水試料に適用した。. 結果 を Table 3 に示す. 本法による分析値 $5.0 \pm 0.1 \mathrm{ng} / \mathrm{ml}$ は保証値 $5.2 \pm 0.3 \mathrm{ng} / \mathrm{ml}$ 並びに他法 ${ }^{6} 5.2 \pm 0.2 \mathrm{ng} / \mathrm{ml}$ の 結果とほぼ一致したことから，本法は比較的セレン濃度 の高い排水, 河川水等の試料への適用が可能であること が分かった。

$\left(\begin{array}{l}1996 \text { 年 } 9 \text { 月, 日本分析化学会第 } 45 \\ \text { 年会において一部発表 }\end{array}\right)$

\section{文 献}

1) 安藤正典: ぶんせき (Bunseki), 1994, 696 .

2）田口幸夫：ぶんせき (Bunseki), 1994, 824

3）田中 茂, 中村 優, 横井英夫, 湯村正徳, 橋本 芳一: 分析化学 (Bunseki Kagaku), 35, 116 (1985).

4) 玉利祐三，吉田昌子, 高木 晋, 茶山健二, 过 治雄, 日下 譲: 分析化学 (Bunseki Kagaku), 41, T77 (1992).

5) Y. Tamari, H. Ogura, K. Fujimori, H. Tsuji: Mem. Konan Univ., Sci. Ser., 43, 37 (1996).

6) 玉利祐三, 茶山健二, 辻 治雄: Biomed. Res. Trace Elements, 4, 263 (1993).

7) Y. Nakaguchi, K. Hiraki, Y. Tamari, Y. Fukunaga, Y. Nishikawa, T. Shigematsu: Anal. Sci., 1, 247 (1985). 
要 旨

水素化物発生原子吸光法（HG-AAS）では，一定条件下でセレン(VI) が検出されずセレン(IV) の みが検出されるので, 試水中の全セレンを定量するためには, 全セレンをセレン(IV) に還元しなけれ ばならない，種々の還元剤について検討したところ，低塩酸濃度の溶液では臭化カリウムを用いる還元 法が優れており詳細な検討の結果, $0.5 \mathrm{~mol} / 1$ 塩酸酸性とした $1.5 \%$ 臭化力りウム溶液で 60 分間煮沸処 理することにより，セレン(VI) がセレン(IV) に定量的に還元できることが分かった. 本法を日本分 析化学会より供給されている河川水標準物質に適用したところ, 満足し得る結果が得られた. 